Health Informatics - An International Journal (HIIJ) Vol.4, No.3/4, November 2015

\title{
Evaluating The Effectiveness of Current Types of Patient Portal Education Efforts
}

\author{
Sajeesh Kumar and Jennifer L Cooper \\ Department of Health Informatics \& Information Management, University of Tennessee \\ Health Science Center, Memphis, TN, USA
}

\begin{abstract}
Engaging patients to be involved in their own health has been a challenge as well as a focus in the health care industry. A patient portal is essentially a personal health record that is housed within a providers' EHR. Once patients have enrolled in the portal they can access it as long as they have internet just as they would a secure website. This study aims to identify the best way to market a patient portal in order to educate patients that one is available for patients to use.
\end{abstract}

\section{KEYWORDS}

Personal health record, electronic health record, Meaningful Use, patient portal

\section{INTRODUCTION}

Engaging patients to be involved in their own health has been a challenge as well as a focus in the health care industry. Patient engagement goes back to encouraging patients to keep track of their records by creating a personal health record (PHR) via paper records that they would request from their providers. As technology has progressed, secure websites have been created to track and maintain this information in an electronic format. With Meaningful Use (MU), part of the electronic health record (EHR) incentive program, the industry has taken patient engagement a step further with the use of patient portals.

A patient portal is essentially a personal health record that is housed within a providers' EHR. Once patients have enrolled in the portal they can access it as long as they have internet just as they would a secure website. For those eligible professionals (EPs) and eligible hospitals (EHs) participating in MU, being able to provide patients access to a portal is a requirement that must be met in order to receive any incentive payments.

HR Medical Center (HRMC), is participating in the EHR incentive program. They have been successful in meeting the first stage of MU which partly required that they provide health information electronically for at least fifty percent of patients discharged as an inpatient or from the emergency department. Having met attestation for this stage, they can proceed to attest for MU stage two. Stage two requires that patients enroll in and use the patient portal within HRMC's EHR. Efforts have been underway to encourage patients to enroll in the portal, but the success rate has been minimal. To be successful in stage two, they must maintain a five percent (5\%) enrollment rate starting October 1, 2015 through September 30, 2016. It is vital that they prepare now in order to meet this requirement.

As incentive programs become available to providers, they are being pushed to encourage their patients to get involved in their care through the use of technology. The problem with this is that trying to educate patients can be difficult when providers only have a limited time with them. Not only this, but patients can be inundated with information that it becomes overwhelming to try DOI: $10.5121 /$ hiij.2015.4401 
and remember one more thing. For the older population technology is not a priority. All they want to know is what they need to do. They expect their provider to explain everything they need to know and that be the end of it.

For HRMC the majority of their inpatient population are Medicare patients. This poses a challenge on how to best educate patients on the existence of the patient portal, how to use it, and the benefits patients can gain from having it available. If HRMC plans to successfully meet MU stage two, they will have to determine the best way to educate their patients about the portal in order to increase their enrollment rate to at least five percent $(5 \%)$.

The purpose of this study is to identify the best way to market a patient portal in order to educate patients that one is available for patients to use. As patients come to the hospital they are given so much paper work that information can be missed by the patient, which could include information about a portal. Is a paper instruction form enough, or do more measures need to be taken to ensure that patients are aware of an existing portal in order to encourage them to enroll in and use the portal? If this question can be answered, the idea is that there will be more people enrolling in and using portals. This can also help answer other questions such as the type of people using the portal and reasons why patients are not using the portal.

In reviewing literature, there have been many studies conducted on how patient portals can help patients manage chronic illnesses when they are part of a disease group. There are also many studies that explain both the benefits and barriers that patients face with portals. Some of the outcomes of these studies have shown the different demographics of those that are and are not enrolling in patient portals. However, there are very few studies that show a best practice for educating patients about portals that result in more participation from patients. Having more knowledge of what works best can help EPs and EHs across the country be successful in not only meeting requirements for $\mathrm{MU}$, but more importantly, getting patients involved in their own care.

The main research question for this study is what is the best format to educate patients that a patient portal is available? Once this question can be answered, the ideal outcome would be an increase in patients enrolling in portals. Another question to consider, specifically for HRMC, is what is the current process for educating patients and is it working? Additional data can be gathered such as barriers preventing patients enrolling in portals and if demographics (such as gender and age) plays a role in enrolling. Recommendations to implement additional education materials in order to continue to enroll patients in the portal can also be a result of this study.

\section{METHOD}

There were two parts to this project. The first involved the creation and implementation of education materials with help from the marketing department at HRMC. Meetings were held with this department to plan how to reach out to and educate patients about the portal. Prior to this project the only form of education of the portal took place at discharge with a brief explanation from the nurses about the portal and an instruction sheet on how to sign up and log in. After meeting with marketing, the following are the education materials that were planned for implementation:

1. $\quad$ Facebook advertisement (Figures 1 and 2)

2. Hospital website banner (Figure 3)

3. Direct mail

4. Email blast 
Unfortunately, due to time constraints and the lack of information needed from other departments, the direct mail and email blast approaches were not carried out.

The second part of this project involved an electronic survey (Figure 4). This was developed to examine the effectiveness of the above patient portal education efforts as well as determine from the patients what improvements can be made. With input from the patient portal committee, the final survey included the following questions:

1. Identification of gender

2. Identification of age

3. Have you heard about MyHuntHealth, our patient portal?

4. Did you sign up for the portal upon hearing about it? If so, indicate how.

5. If you signed up for the portal, did you have any initial problems logging in? If so, please describe the problem.

6. If you did not sign up for the portal, please indicate why you chose not to.

7. Is there a feature / function you would like to see in the portal such as scheduling, integrated bills, physician messaging, etc? If so, please describe.

8. Do you have any suggestions on how we can better communicate with our patients the existence and benefits of our patient portal?

Questions and rationale. The following includes more information regarding the survey questions such as answer choices and the reason for the question.

Gender and age. Survey choices for gender were: Male or Female. Age was left open for the patients to fill in their age. Rationale: The gender and age were captured to determine the demographics of patients that have heard about the portal. This can later provide insight into additional ways to market the portal to a particular group of people. Have you heard about, our patient portal? Survey choices were: Yes or No. Rationale: This answers the question of whether the patient heard about the portal or not.

Did you sign up for the portal upon hearing about it? If so, how? If the patient answered yes, the survey choices were: a) Facebook advertisement; b) From the nurses at the time of discharge; c) Hospital website banner; d) instruction sheet in the discharge packet (Figure 5); e) Word of mouth; f) Other. Rationale: This answers the question of how the patient heard about the portal. The options provided were current education efforts that were in place prior to the project as well as those additional materials that were created.

If you signed up for the portal, did you have any initial problems logging in? If so, please explain the issue. Survey choices were: Yes or No. Rationale: The patient portal committee was interested in responses to this question in order to make any necessary improvements during the $\log$ in process. They do not want patients to deter from signing up for the portal based on technical difficulties.

If you did not sign up for the portal, please indicate why you chose not to. Survey choices were: a) Disinterest; b) I rely on my doctor for this information; c) It is easier to request my medical records and have them printed; d) Limited us of, or access to, a computer; e) Portal content is not useful; f) Unaware of the existence of the portal; g) Other. Rationale: This information was captured to determine what barriers are causing patients to not sign up for the portal.

Is there a feature / function you would like to see in the portal such as scheduling, integrated bills, physician messaging, etc? If so, please describe. Survey choice: this was an open ended 
question. Rationale: The patient portal committee wanted feedback from patients to see what else could be added to the portal that they would find beneficial.

Do you have any suggestions on how we can better communicate with our patients the existence and benefits of our patient portal? Survey choice: this was an open ended question. Rationale: The patient portal committee wanted to learn from patients if there were additional ways they could provide education about the portal to potentially try in the future in order to enroll more patients.

Approval of the project came from the compliance committee. Those that represented this committee included the Assistant Administrator, Director of Decision Support, and the HIPAA Privacy Officer. They determined that the nature of the project was operational with marketing as the means for completing the project. They were sent the survey questions for review and approval. There were no concerns from a HIPAA perspective as far as a need for special consent.

Population and Sample Size

When the Medical Center attested to MU stage one, which required them to electronically provide at least fifty percent of health information for inpatient and observation discharges or emergency department visits, they only attested with information from inpatient and observation discharges. In order to attest for MU stage two, which includes patient portal enrollment, they can only account for inpatient and observation discharges. As a result, the sample size for this project was based on the following criteria:

1. The patient must have been discharged as an inpatient or observation during the month of February. Rationale: The new education materials went out throughout the month of February.

2. The patient must be nineteen (19) years or older. Rationale: Patients eighteen (18) years and younger are not able to sign up for the portal.

3. The patient must have an email address. Rationale: The idea was that patients who have an email address were more likely to sign up for the portal if they heard about it.

Based on the above, 201 patients met the criteria. The goal was to survey $100 \%$ of these patients in order to get a good sample with the anticipation that patients would not respond to the survey. After analyzing the 201 patients discharged in February that met the criteria, fifteen (15) were repeat patients. Once the survey was sent out via email, thirteen (13) were rejected meaning the email address the patient had listed was invalid. The final sample size was 173 patients.

\section{Data Collection Instrument}

The database used to complete this project was the Research Electronic Data Capture (REDCap) database. REDCap is a secure web application designed for building and managing online surveys and databases created by Vanderbilt University and made available for use through the University of Tennessee Health Science Center (UTHSC). The survey was developed and administered through REDCap. The survey itself was set up using branching logic so patients were only required to answers questions based on their answer choices. As patients responded to the survey, the REDCap database captured the responses which made for easy data analysis.

\section{Data Collection Procedures}

For patients that met the criteria to receive the survey, a cover letter (Figure 6) was sent as an email message which included a link to the survey. The email / survey was sent on Monday, 
Health Informatics - An International Journal (HIIJ) Vol.4, No.3/4, November 2015

March 9, 2015 with a reminder email sent Wednesday, March 18, 2015. The deadline to complete the survey was Friday, March 20, 2015.

\section{Data Analysis}

Results from the survey were exported from REDCap into Microsoft Excel for data analysis. In addition to Excel, the report builder in REDCap was used for cross tabulation of different variables. All tables were created in Excel.

\section{RESULTS}

\section{Response rate of Sample / Population}

Out of 173 sent surveys, a total of twenty-five (25) responses were received via REDCap for a response rate of $14 \%$. The first request yielded eighteen (18) responses. Seven (7) additional responses were yielded after the reminder email was sent. All responses were complete.

\section{Survey Question Responses}

Summaries of the counts and percentages of the survey questions are listed in Tables 1 through 7 . Responses that were excluded from these tables include those with an "other" choice that required an explanation. Also excluded were the final two questions on the survey. These questions were optional, open ended questions. They asked the respondents to provide feedback on other functions they would like to see in the portal, and suggestions on how else HRMC could communicate the existence of the portal to their patients. Tables 8 through 13 represent cross tabulations of different variables.

\section{Table 1 Gender}

\begin{tabular}{lll}
\hline Gender & $\begin{array}{l}\text { No. } \\
\text { Respondents }\end{array}$ & of \\
Male & 10 & $40 \%$ \\
& 15 & $60 \%$ \\
Female & & \\
Total & $\mathbf{2 5}$ & $\mathbf{1 0 0 \%}$ \\
\hline
\end{tabular}

Figure 7Age

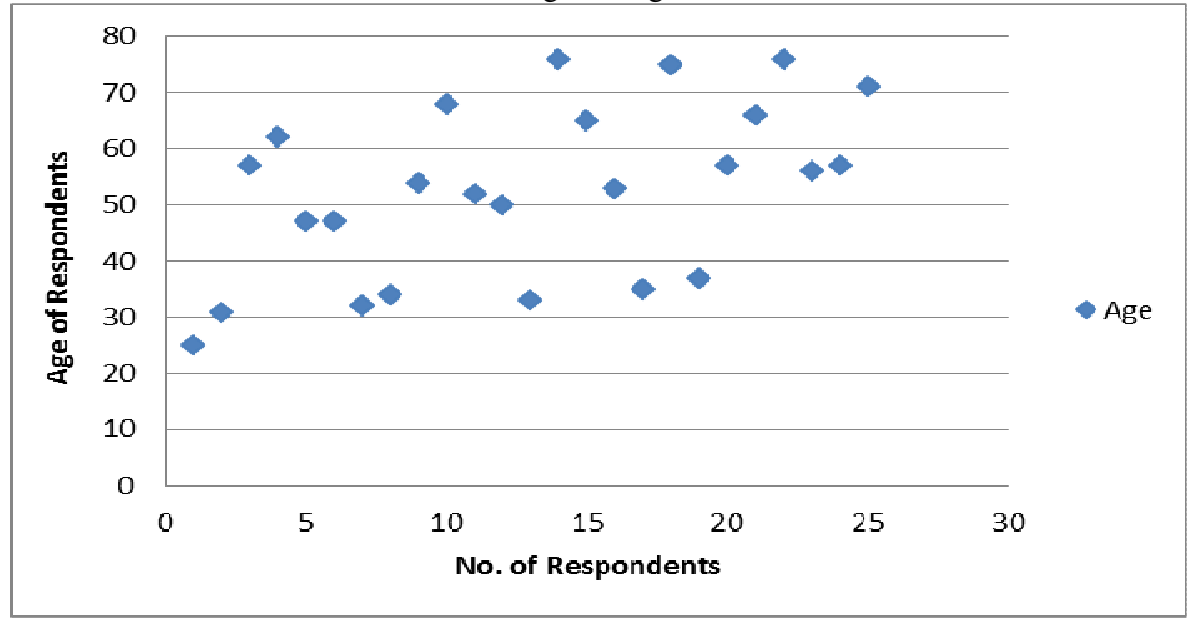


Health Informatics - An International Journal (HIIJ) Vol.4, No.3/4, November 2015

Table 2 Age Range

\begin{tabular}{lll}
\hline Age range & No. of Respondents & Percent of Total Respondents \\
\hline $19-24$ & 0 & $0 \%$ \\
$25-34$ & 5 & $20 \%$ \\
$35-44$ & 2 & $8 \%$ \\
$45-54$ & 6 & $24 \%$ \\
$55-64$ & 5 & $20 \%$ \\
$65+$ & 7 & $28 \%$ \\
Total & 25 & $\mathbf{1 0 0 \%}$ \\
\hline
\end{tabular}

Table 3 Have you heard about MyHuntHealth, our patient portal?

\begin{tabular}{lll}
\hline Heard of portal & No. of Respondents & Percent of Total Respondents \\
\hline Yes & 16 & $64 \%$ \\
No & 9 & $36 \%$ \\
Total & $\mathbf{2 5}$ & $\mathbf{1 0 0 \%}$ \\
\hline
\end{tabular}

Table 4 Did you sign-up for the portal upon hearing about it?

\begin{tabular}{lll}
\hline Did you sign-up & No. of Respondents & Percent of Total Respondents \\
\hline Yes & 12 & $75 \%$ \\
No & 4 & $25 \%$ \\
Total & $\mathbf{1 6}$ & $\mathbf{1 0 0 \%}$ \\
\hline
\end{tabular}


Health Informatics - An International Journal (HIIJ) Vol.4, No.3/4, November 2015

Table 5 Please indicate how you heard about the portal.

\begin{tabular}{lll}
\hline $\begin{array}{l}\text { How did you hear about the } \\
\text { portal? }\end{array}$ & $\begin{array}{l}\text { No. } \\
\text { Respondents }\end{array}$ & of \\
\hline Facebook & 0 & $0 \%$ \\
From the nurses at discharge & 2 & $16.7 \%$ \\
Hospital website banner & 2 & $16.7 \%$ \\
MyHuntHealth instruction & & \\
sheet & 3 & $25 \%$ \\
Word of mouth & 1 & $8.3 \%$ \\
Other & 4 & $33.3 \%$ \\
& & \\
Total & $\mathbf{1 2}$ & $\mathbf{1 0 0 \%}$ \\
\hline
\end{tabular}

Table 6 If you signed-up for the portal, did you have any initial problems logging in?

\begin{tabular}{lll}
\hline Log-in problems & No. of Respondents & Percent of Total Respondents \\
\hline Yes & 1 & $8.3 \%$ \\
No & 11 & $91.7 \%$ \\
Total & $\mathbf{1 2}$ & $\mathbf{1 0 0 \%}$ \\
\hline
\end{tabular}

Table 7 If you did not sign-up for the portal, please indicate why you chose not to.

\begin{tabular}{lll}
\hline Reason for not signing-up & $\begin{array}{l}\text { No. } \\
\text { Respondents }\end{array}$ & $\begin{array}{l}\text { of } \\
\text { Percent of Total } \\
\text { Respondents }\end{array}$ \\
\hline Disinterest & 0 & $0 \%$ \\
I rely on my doctor for this information & 2 & $50 \%$ \\
$\begin{array}{l}\text { It is easier to request my medical records and have them } \\
\text { printed }\end{array}$ & 0 & $0 \%$ \\
Limited use of, or access to, a computer & 1 & $25 \%$ \\
Portal content is not useful & 0 & $0 \%$ \\
Unaware of the existence of the portal & 0 & $0 \%$ \\
Other & 1 & $25 \%$ \\
Total & $\mathbf{4}$ & $\mathbf{1 0 0 \%}$ \\
\hline
\end{tabular}


Health Informatics - An International Journal (HIIJ) Vol.4, No.3/4, November 2015

Table 8 Cross tabulation of respondents that signed-up for the portal and their age.

\begin{tabular}{|c|c|c|}
\hline $\begin{array}{lr}\text { Age } & \text { of } \\
\text { Respondents } & \text { that } \\
\text { Signed-up } & \\
\end{array}$ & $\begin{array}{ll}\text { No. } & \text { of } \\
\text { Respondents } & \\
\end{array}$ & Percent of Total Respondents \\
\hline $19-24$ & 0 & $0 \%$ \\
\hline $25-34$ & 3 & $25 \%$ \\
\hline $35-44$ & 1 & $8 \%$ \\
\hline $45-54$ & 4 & $33 \%$ \\
\hline $55-64$ & 2 & $17 \%$ \\
\hline $65+$ & 2 & $17 \%$ \\
\hline Total & 12 & $100 \%$ \\
\hline
\end{tabular}

Table 9 Cross tabulation of respondents that signed-up for the portal and their gender.

\begin{tabular}{|c|c|c|}
\hline $\begin{array}{lr}\text { Gender } & \text { of } \\
\text { Respondents } & \text { that } \\
\text { Signed-up } & \\
\end{array}$ & No. of Respondents & Percent of Total Respondents \\
\hline Male & 4 & $33 \%$ \\
\hline Female & 8 & $67 \%$ \\
\hline Total & 12 & $100 \%$ \\
\hline
\end{tabular}

Table 10 Cross tabulation of the age of the respondents that signed-up for the portal and how they heard about the portal.

\begin{tabular}{lllllll}
\hline Age Range & Facebook & $\begin{array}{l}\text { From the } \\
\text { nurses } \\
\text { discharge }\end{array}$ & $\begin{array}{l}\text { Hospital } \\
\text { website } \\
\text { banner }\end{array}$ & $\begin{array}{l}\text { Instruction } \\
\text { sheet }\end{array}$ & $\begin{array}{l}\text { Word } \\
\text { of } \\
\text { mouth }\end{array}$ & Other \\
\hline $19-24$ & 0 & 0 & 0 & 0 & 0 & 0 \\
$25-34$ & 0 & 0 & 2 & 0 & 0 & 1 \\
$35-44$ & 0 & 0 & 0 & 1 & 0 & 0 \\
$45-54$ & 0 & 1 & 0 & 1 & 0 & 2 \\
$55-64$ & 0 & 0 & 0 & 1 & 0 & 1 \\
$65+$ & 0 & 1 & 0 & 0 & 1 & 0 \\
Total & $\mathbf{0}$ & $\mathbf{2}$ & $\mathbf{2}$ & $\mathbf{3}$ & $\mathbf{1}$ & $\mathbf{4}$ \\
\hline
\end{tabular}


Health Informatics - An International Journal (HIIJ) Vol.4, No.3/4, November 2015

Table 11 Cross tabulation of respondents that did not sign-up for the portal and their age.

\begin{tabular}{lll}
\hline $\begin{array}{l}\text { Age of Respondents } \\
\text { that Did Not Sign-up }\end{array}$ & No. of Respondents & Percent of Total Respondents \\
\hline $19-24$ & 0 & $0 \%$ \\
$25-34$ & 1 & $25 \%$ \\
$35-44$ & 0 & $0 \%$ \\
$45-54$ & 0 & $0 \%$ \\
$55-64$ & 1 & $25 \%$ \\
$65+$ & 2 & $50 \%$ \\
Total & $\mathbf{4}$ & $\mathbf{1 0 0 \%}$ \\
\hline
\end{tabular}

Table 12 Cross tabulation of respondents that did not sign-up for the portal and their gender.

\begin{tabular}{lll}
\hline $\begin{array}{l}\text { Gender } \\
\text { Respondents }\end{array}$ & \multicolumn{1}{c}{ of } \\
that & & \\
Did Not Sign-up & No. of Respondents & Percent of Total Respondents \\
\hline Male & 2 & $50 \%$ \\
Female & 2 & $50 \%$ \\
Total & 4 & $\mathbf{1 0 0 \%}$ \\
\hline
\end{tabular}

Table 13 Cross tabulation of the age of the respondents that did not sign-up for the portal and the reason why.

\begin{tabular}{|c|c|c|c|c|c|c|c|}
\hline $\begin{array}{l}\text { Age } \\
\text { Range }\end{array}$ & Disinterest & $\begin{array}{l}\text { I rely on my } \\
\text { doctor for } \\
\text { this } \\
\text { information }\end{array}$ & $\begin{array}{l}\text { It is easier } \\
\text { to request } \\
\text { my } \\
\text { medical } \\
\text { records and } \\
\text { have them } \\
\text { printed }\end{array}$ & $\begin{array}{l}\text { Limited use } \\
\text { of, or access } \\
\text { to, } \\
\text { computer a }\end{array}$ & $\begin{array}{l}\text { Portal } \\
\text { content } \\
\text { is not } \\
\text { useful }\end{array}$ & $\begin{array}{l}\text { Unaware } \\
\text { of the } \\
\text { existence } \\
\text { of the } \\
\text { portal }\end{array}$ & Other \\
\hline $19-24$ & 0 & 0 & 0 & 0 & 0 & 0 & 0 \\
\hline $25-34$ & 0 & 1 & 0 & 0 & 0 & 0 & 0 \\
\hline $35-44$ & 0 & 0 & 0 & 0 & 0 & 0 & 0 \\
\hline $45-54$ & 0 & 0 & 0 & 0 & 0 & 0 & 0 \\
\hline $55-64$ & 0 & 0 & 0 & 1 & 0 & 0 & 0 \\
\hline $65+$ & 0 & 1 & 0 & 0 & 0 & 0 & 1 \\
\hline Total & 0 & 2 & 0 & 1 & $\mathbf{0}$ & 0 & 1 \\
\hline
\end{tabular}


Health Informatics - An International Journal (HIIJ) Vol.4, No.3/4, November 2015

\section{DISCUSSION}

Tables 1 and 2 essentially show the demographics, in terms of gender and age, that HRMC serves. Ten (10) of the respondents were male, while fifteen (15) were female. The age range with the highest respondents came from those that were sixty-five (65) years and older, with a total of seven (7) respondents. There were zero respondents in the nineteen (19) to twenty-four (24) age range. The rest of the results show that there were five (5) respondents between the ages of twenty-five (25) and thirty-four (34). Only two (2) respondents fell in the thirty-five (35) to forty-four (44) age range. Six (6) respondents represented those in the age range between fortyfive (45) and fifty-four (54). Finally, five (5) respondents, were in the age range between fiftyfive (55) and sixty-four (64).

Table 3 shows that of the twenty-five (25) respondents, sixteen (16) of them had heard of the portal at HRMC. This left nine (9) respondents that had not heard of the portal.

Of the sixteen (16) respondents that did hear about the portal, only twelve (12) signed-up for the portal, leaving four (4) that did not sign-up for the portal (Table 4).

Table 5 explains how the respondents heard about the portal. Two Facebook advertisements were created and posted throughout the month of February (Figures $\mathrm{x} \& \mathrm{x}$ ). One was targeted towards the general population, male and female, in the twenty-five (25) to sixty-four (64) age range. The other was targeted towards the maternity population in the age range of eighteen (18) to fortyfour (44). These advertisements generated 431 unique clicks, meaning people who clicked on the advertisement on Facebook were directed to the patient portal page on HRMC's hospital website. Despite the numerous clicks from the Facebook advertisement to the portal page on the hospital website, none of the respondents from this survey heard about the portal via the Facebook advertisements. Two (2) respondents heard about the portal from the nurses at discharge, while three (3) found the information from the instruction sheet in the discharge packet. The hospital website banner with the portal information is where two (2) of the respondents heard about the portal. One (1) respondent found out about the portal via word of mouth. Finally, four (4) respondents heard about the portal through other means. The "other" options listed by the four (4) respondents included email, employee, and emergency room check-in.

For the twelve (12) respondents that signed-up for the portal, only one (1) expressed having issues with the log-in process. The respondent described that there was no other resolution than contacting the information systems department to resolve the issue (Table 6).

Table 7 explains the reason why the four (4) respondents did not sign-up for the portal. Two (2) said that they rely on their doctor for the information that is contained in the portal. One (1) said they have limited use or, or access to, a computer. The final respondent in this category chose "other" as their reason which was stated as giving up due to difficulties with the log-in process.

Table 8 is the first of six cross tabulation tables. This table shows the age range of the twelve (12) respondents that signed-up for the portal. There were no respondents to sign-up for the portal in the nineteen (19) to twenty-four (24) age range. Three (3) respondents were in the twenty-five (25) to thirty-four (34) age range. Only one (1) respondent was in the age range of thirty-five (35) to forty-four (44). The age range with the most respondents was forty-five (45) to fifty-four (54). This equaled four (4) respondents. There were two (2) respondents in both the fifty-five (55) to sixty-four (64) age range and sixty-five (65) and older range. 
Health Informatics - An International Journal (HIIJ) Vol.4, No.3/4, November 2015

Table 9 identified the male verses female respondents that signed-up for the portal. Of the twelve (12) respondents, four (4) were male and eight (8) were female. Table 10 shows how each age range heard about the portal. There were two (2) in the twenty-five (25) to thirty-four (34) range that heard about it via the hospital website banner. In this same range, one (1) respondent heard about it through other means. In the thirty-five (35) to forty-four (44) range, one (1) respondent heard of the portal from the instruction sheet. For respondents in the forty-five (45) to fifty-four (54) range, one (1) heard about the portal from the nurses at discharge, one (1) heard from the instruction sheet, and one (1) heard about it through other means. One (1) respondent heard about the portal from the instruction sheet, and one (1) from other means in the fifty-five (55) to sixtyfour (64) range. Finally, in the sixty-five (65) plus range, one (1) respondent heard about the portal from the nurses at discharge, and one (1) by word of mouth.

Table 11 shows the age range of the four (4) respondents that did not sign-up for the portal. There was one (1) respondent in both the twenty-five (25) to thirty-four (34) and fifty-five (55) to sixty-four (64) ranges. There were two (2) respondents in the sixty-five (65) plus range.

Table 12 identified the male verses female respondents that did not sign-up for the portal. Of the four (4) respondents, there was a fifty / fifty split of males and females.

Table 13 states the reasons, by age range, of those respondents that did not sign-up for the portal. The one (1) respondent in the twenty-five (25) to thirty-four (34) range chose that they rely on their doctor for the information contained in the portal as their reason for not signing-up. Limited use of, or access to, a computer was the reason for the one (1) respondent in the fifty-five (55) to sixty-four (64) range. There were two (2) respondents in the sixty-five (65) plus range that did not sign-up. The reasons were listed as relying on their doctor and other. The respondent that chose other described the reason as having difficulty with the log-in process so they gave up on attempting to sign-up.

\section{Limitations}

The section below outlines limitations of the study that should be considered.

- The study is specific to HRMC, so generalizing the information may be difficult. However, the concepts behind the study could apply to any EP or EH that are trying to determine a best practice to educate patients about their portal.

- Despite efforts to encourage participation in the survey (iPad Mini give away) the response rate was low at only fourteen percent (14\%). This did not allow for adequate data analysis to determine what form of communication is working the best for HRMC.

- Not only was the response rate low, but an error occurred in setting up the branching logic within the survey. Of the twenty-five (25) respondents, sixteen (16) acknowledged that they heard about the portal. This should have yielded sixteen (16) responses to the question "Please indicate how you heard about the portal." However, only respondents that answered "Yes" to the question "Did you sign-up for the portal upon hearing about it?" were directed to answer how they heard about the portal. Due to this error, there were four (4) less responses to how patients heard about the portal.

- There was no way to identify if the respondents that did sign-up for the portal signed-up during the month of February when the additional education efforts were implemented. 
- Two (2) respondents described "Email" as the "Other" option for how they heard about the portal. Per the marketing director and consensus from the patient portal committee, no emails have been sent out from HRMC regarding the MyHuntHealth portal. These respondents did not provide an accurate representation of how they actually heard about the portal.

- Due to time constraints and limited resources, not all of the planned education materials were implemented. Specifically, the direct mail and email blast materials were not sent. These materials would have provided more ways for patients to hear about the portal.

- When searching for relevant articles that discuss effective education measures for portal enrollment, there were limited returns. This does not allow for a comparison between the results of this studies and others like it.

\section{Conclusions}

This study allowed various ways for patients to hear about the portal through means of social media, information on the hospital website, verbal discussions with hospital staff, and an instruction form. However, the lack of survey responses did not provide enough data to truly evaluate what form of education is working the best as far as causing an increase in patients enrolling in the portal. From the data that is available, the results indicated that patients heard about the portal mostly from the instruction form and subsequently signed-up. This is surprising as this form has been in place since 2014 yet the enrollment rate is not where HRMC would like it to be. From the literature review results, there was one article with a similar study. The study consisted of three different education tactics. One was through a video shown in the patient's room as they waited to be seen, the other was via an instruction form, and the final means of education was no additional promotion of the portal. The instruction form increased enrollment rate by $7.1 \%$. What can be gathered from this article and the results of the study is that instruction forms can be effective.

Other conclusions that can be drawn from the study that are not related to the initial research question include the following:

The results of the study first show that more females have not only heard about the portal, but have also signed-up for the portal. Prior to these results, the patient portal committee at HRMC discussed that it would be likely for more females to sign-up than males. There was no reason behind why, but the results do validate this. Literature that incorporated demographic information also showed that females signed-up for portals more than males.

An assumption was made that there would be limited participation in the portal from the older population that Medical Center serves. The results show that four (4) of the respondents that signed-up for the portal fell in the forty-five (45) to fifty-four (54) age range. This was the most out of all the age ranges. Although this is the middle age range, there were still participants fiftyfive (55) and older that have signed-up. What was unexpected was the limited participation from the younger age ranges. Literature revealed that young adults were more likely to sign-up for portals. There were no survey respondents in the nineteen (19) to twenty-four (24) range. Also, only one (1) respondent that signed-up for the portal represented the thirty-five (35) to forty-four (44) range. From these results, it appears that it may be more difficult to reach out to the younger population rather than the older population. 
There was concern from the patient portal committee that patients would not want to enroll in the portal due to limited functionality as well as disinterest in the portal. Per the results, these were not a factor in why respondents did not sign-up for the portal. The main reason for not signing-up was that respondents felt that their doctors should communicate with them information about their health.

Implications of Study

For Medical Center, this study validates that their instruction form is working in terms of patients enrolling as a result of having the form. It also showed what is not working so that HRMC does not continue putting resources into the wrong areas - more specifically, the Facebook advertisements. As a result of the cross tabulations of the data, the study provides insight into age ranges of people that are hearing about the portal and how they are hearing about it as well as some of the barriers. This can allow marketing to develop materials that target specific age groups to help increase the enrollment rate.

\section{Recommendations}

Even with few survey responses, this study was able to identify what current education materials were effective. There is room to continue to refine methods of education, such as implementing the suggestions expressed by the respondents as a result of the survey. The suggestions included 1) notifying patients at admission; 2) direct mail; 3) email; 4) a video on the hospital channel; and 5) training classes. What this study could not do was provide a value to quantify these results with the actual enrollment rate due to limitations of Medical Center's electronic health record. There are future upgrades to the system in progress that include additional functions to the portal. If these upgrades can track and trend enrollment activity, and additional education materials are implemented, a follow-up survey may be beneficial to revisit Medical Center's enrollment progress in relation to how they are communicating the portal to their patients.

\section{ACKNOWLEDGEMENTS}

The authors would like to thank the faculty at Department of Health Informatics and Information Management, University of Tennessee.

\section{REFERENCES}

[1] Bergman, D. A., Brown, N. L., and Wilson, S. (2008). Teen use of a patient portal: A qualitative study of parent and teen attitudes. Perspectives in Health Information Management, 5. Retrieved from http://www.ncbi.nlm.nih.gov/pmc/articles/PMC2556441/

[2] Goel, M. S., Brown T. L., Williams, A., Hasnain-Wynia, R., Thompson, J. A., and Baker, D. W. (2011). Disparities in enrollment and use of an electronic patient portal. Journal of General Internal Medicine, 26, 1112-1116. doi 10.1007/s11606-011-1728-3

[3] Goel, M. S., Brown T. L., Williams, A., Cooper, A. J., Hasnain-Wynia, R., and Baker, D. W. (2011). Patient reported barriers to enrolling in a patient portal. Journal of the American Medical Informatics Association, 18, i8-i12. doi 10.1136/amiajnl-2011-000473

[4] North, F., Hanna, B. K., Crane, S. J., Smith, S. A., Tulledge-Scheitel, S. M., and Stroebel, R.J. (2011). Patient portal doldrums: Does an exam room promotional video during an office visit increase patient portal registrations and portal uses?. Journal of the American Medical Informatics Association, 18, i24-i27. doi 10.1136/amiajnl-2011-000381

[5] Weingart, S. N., Rind, D., Tofias, Z., and Sands, D. Z. (2006). Who uses the patient portal? The PatientSite experience. Journal of the American Medical Informatics Association, 13, 91-95. doi 10.1197/jamia.M1833 
Health Informatics - An International Journal (HIIJ) Vol.4, No.3/4, November 2015

Figure 1 Scatter diagram of the age of respondents

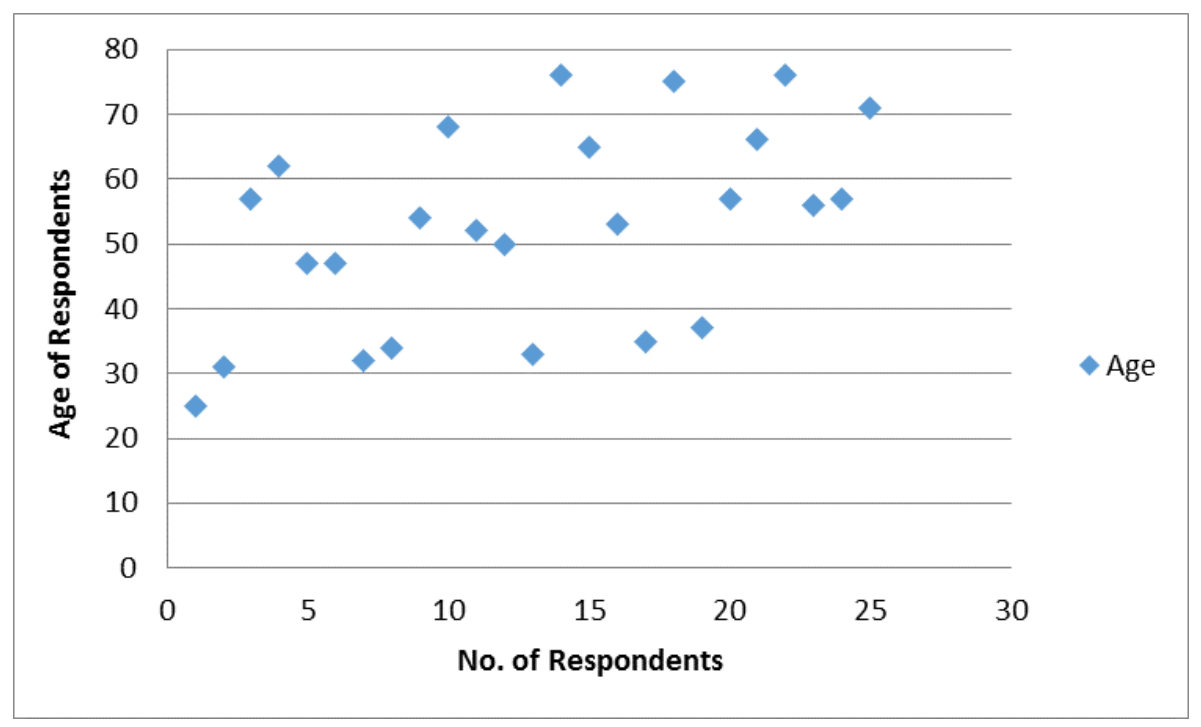

\section{AUTHOR}

Sajeesh Kumar, PhD., is Executive Director- Institute for Health Outcomes and Policy, Chair-Health Outcomes and Policy Research PhD program and Associate Professor, Department of Health Informatics \& Information Management, University of TennesseeMemphis. Dr. Kumar's research focuses on design and development of public health informatics, telemedicine technology, health education technologies and health informatics technology evaluation. Dr. Kumar holds an impressive record of competitive

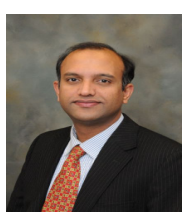
research funding and research awards. 